\title{
To Study the Effect of M-Learning Knowledge Management Programme on the Performance of Teacher Trainees Belonging To Different Residential Backgrounds
}

\author{
Ruchi Tomar ${ }^{1 *}$, Dr. Vinita S. Gopalkrishanan ${ }^{2}$
}

\section{ABSTRACT}

This paper discusses implementation of M-learning with appropriate knowledge management in teacher education for planning and delivering lessons during practice teaching for enhancing their performance. Main objective of study was to study the effectiveness of M-learning knowledge management on the performance of teacher trainees. Sample chosen for the present study was 52 teacher trainees. For analysis of data ANOVA was applied and results were taken out subsequently. And findings suggest that knowledge management in M-learning enhance performance of teacher trainees. Further findings revels that residential background also affects performance i.e. urban based teacher trainees performs better than that of rural teacher trainees. Results taken out from that data collected from schools students regarding the performance of teacher trainee's revels that there was no significant effect of residential background on the performance of teacher trainees.

Keywords: M-Learning, Management Programme, Teacher Trainees, Residential Backgrounds.

Mobile technologies are everywhere; it is involved in almost every part of our lives today. During communication or performing day to day tasks revolutionary changes has been brought about with the advent of mobile devices. These devices not only help in communications, shopping, bill payments, money transfer, entertainment, receiving various information's etc. but it also has lot of potential to contribute to the field of education and training. M-learning supports learning by assisting user to improve literateness and numeric skills and thereby helping them to search for their prevailing abilities. It supports both personal and collaborative learning. It supports learner at the time of assistance needed. It helps learner to overcome the digital divide, and making learning informal. Learners remain focused for longer time, and it also enhances their confidence and self-esteem. Mobile devices are portable, widely used, and more known as

\footnotetext{
${ }^{1}$ Research Scholar, Banasthali Vidyapith, Rajasthan.

${ }^{2}$ Associate Professor, Education Faculty, Banastahli Vidyapith, Rajasthan

*Responding Author

(C) 2016 I R Tomar, V Gopalkrishanan; licensee IJIP. This is an Open Access Research distributed under the terms of the Creative Commons Attribution License (http://creativecommons.org/licenses/by/2.0), which permits unrestricted use, distribution, and reproduction in any Medium, provided the original work is properly cited.
} 


\section{To Study the Effect of M-Learning Knowledge Management Programme on the Performance of Teacher Trainees Belonging To Different Residential Backgrounds}

compare to ICT supports and requires very less other prior conditions. It is relatively inexpensive, as mobile devices are less expensive then PC and laptop. M-learning is cost effective for learning, teaching and training. Some features that make mobile device a unique learning experience as they are faster, lighter and thinner then ICT supports. The distinguishing feature of learning through mobile devices they are mobile, flexible, easily accessible, convenient, expedient, context based, interactive and reusable to any information during acquisition of knowledge.

The educational technologies mainly observed in classrooms are dependent on teacher and learners elaborate participation even today. This lack leads to search for new approaches for learning. Here M-learning seems to be extremely promising in the felid of teaching and learning. For implementing M-learning into classrooms more effectively teacher should be prepared and trained for it, is the pre-requisite. In that case it would do much better if it is implemented at the stage of teacher training (pre-service teacher training programs). Because mobile learning is the next learning, that is happening wide spread.

Mobile learning is a vast area to know about and one cannot recognize it as a whole. For its easy and effective implementation one can adopt appropriate strategy of knowledge management into it. Knowledge management is the collection of the practices that administers the formation, distribution and application of knowledge for it best consumption amongst people and organizations. Knowledge management elevate information faster between the two or more people. Sharing and transferring knowledge is one of the crucial aspects of knowledge management.

Knowledge management in M-learning is when learner places all existed and required tools and features of knowledge management in M-learning to subsequently plan and control certain objectives and the means to achieve them in an organized manner with least efforts. Knowledge management can be done in mobile device by creating, assimilating and disseminating knowledge. Features of knowledge management can support user during implementation of $\mathrm{M}$ learning to improve their ease and performance.

All the activities in the field of teaching and learning are ultimately done to enhance performance of teacher and learner. Performance here means the level of success and quality of task done by the teacher and learner. Performance can be judged to be good or bad on the basis of some fixed criterion. Performance is one of the most important aspects that can never be overlooked in the classroom while doing certain task to attain specific aim in contract to some known standards. M-learning knowledge management seems truly perspective for improving the performance of prospective teachers (teacher trainees). 


\section{To Study the Effect of M-Learning Knowledge Management Programme on the Performance of Teacher Trainees Belonging To Different Residential Backgrounds}

\section{OBJECTIVE}

1. To study the effect of M-learning knowledge management, residential background and their interaction on performance amongst teacher trainees. (Through self-assessment and student's assessment.)

\section{Hypothesis}

1. There will be no significant difference between m-learning knowledge management, residential background and their interaction on performance amongst teacher trainees. (Through self-assessment and student's assessment.)

\section{METHODOLOGY}

In the present study, amongst various institutions running teacher training courses, one of the institute was selected randomly. For further sample selection 52 teacher trainees through stratified random sampling were chosen. The present study was experimental in nature following single group post-test design. For this study prior orientation about the M-learning knowledge management program was given to participants of the study. Followed by it participant carried out present experiment in real classroom for 40 days. And afterwards they filled appropriate required tools.

\section{Population of the Study}

Populations for the present study were all 100 students enrolled in randomly selected teacher training institute.

\section{Selection of the Sample}

Sample for the present study was selected trough stratified random sampling, where 52 teacher trainees were selected for the study.

\section{Variables}

Three independent variables for the present study are Knowledge Management, M-Learning, residential background. And dependent variable was performance.

\section{Tool Used}

For this study three self-made tools were used named Mobile- knowledge Management inventory and self-performance assessment questionnaire and teacher's performance assessment questioner.

\section{Analysis and Interpretation of Data}

To study the objective, effect of m-learning knowledge management, residential background and their interaction on performance (through self-assessment) was analyzed using ANOVA (Analysis of covariance.) The two levels of residential background were rural and urban. The 


\section{To Study the Effect of M-Learning Knowledge Management Programme on the Performance of Teacher Trainees Belonging To Different Residential Backgrounds}

performance was studied on the basis of self-assessment and students assessment. Thus data were analyzed with the help of factorial design ANOVA for the stated criteria and the results followed by their interpretations are given in the following captions.

As mentioned earlier the two levels of residential background were rural and urban. The data were analyzed with the help of $2 \times 2$ factorial designs ANOVA. The results are given in table.

Table: 1.1 Summary of Factorial Design ANOVA for Performance. ( $N=52)$

\begin{tabular}{|l|l|l|l|l|}
\hline Source of Variance & df & SS & MSS & F \\
\hline $\begin{array}{l}\text { M-learning Knowledge } \\
\text { Management }\end{array}$ & 1 & 1233.88 & 1233.88 & 20.39 \\
\hline Residential Background & 1 & 264.64 & 264.64 & 4.37 \\
\hline A x B & 1 & 177.99 & 177.99 & 2.94 \\
\hline Error & 48 & 2904.16 & 60.50 & \\
\hline Total & 52 & 592778.00 & & \\
\hline
\end{tabular}

*Significant at 0.05 level

\section{1.a Effect of M-learning knowledge Management on performance}

From the table 1.1, it can be observed that the F-value for M-learning Knowledge Management is 20.39 which are significant. It reflects that mean score of performance differ significantly. Thus there was significant effect of M-learning knowledge management on performance of teacher trainees. In this context, the null hypothesis that 'there is no significant effect of Mlearning knowledge management on performance of teacher trainee's', is rejected. It may, therefore be said that the performance was affected significantly by M-learning knowledge management. In order to study the trend of effect of M-learning knowledge management on performance the graph 1.1 has been plotted.

\section{1.b Effect of Residential Background on Performance}

The F-value for Residential Background is 4.37 (Vide Table 1.1) which is significant. It indicates that the mean score of performance of urban as well as rural differ significantly. So Residential Background influences the performance of teacher trainees. In this light, the null hypothesis that there is no significant effect of Residential Background on performance is rejected. It may therefore, be concluded that performance was found to be dependent of Residential Background. In order to study the trend of effect of Residential Background on performance the graph 1.1 has been plotted below. 


\section{To Study the Effect of M-Learning Knowledge Management Programme on the Performance of Teacher Trainees Belonging To Different Residential Backgrounds}

Graph no. 1.1. Effect of M-learning Knowledge Management and Residential Background on the performance.

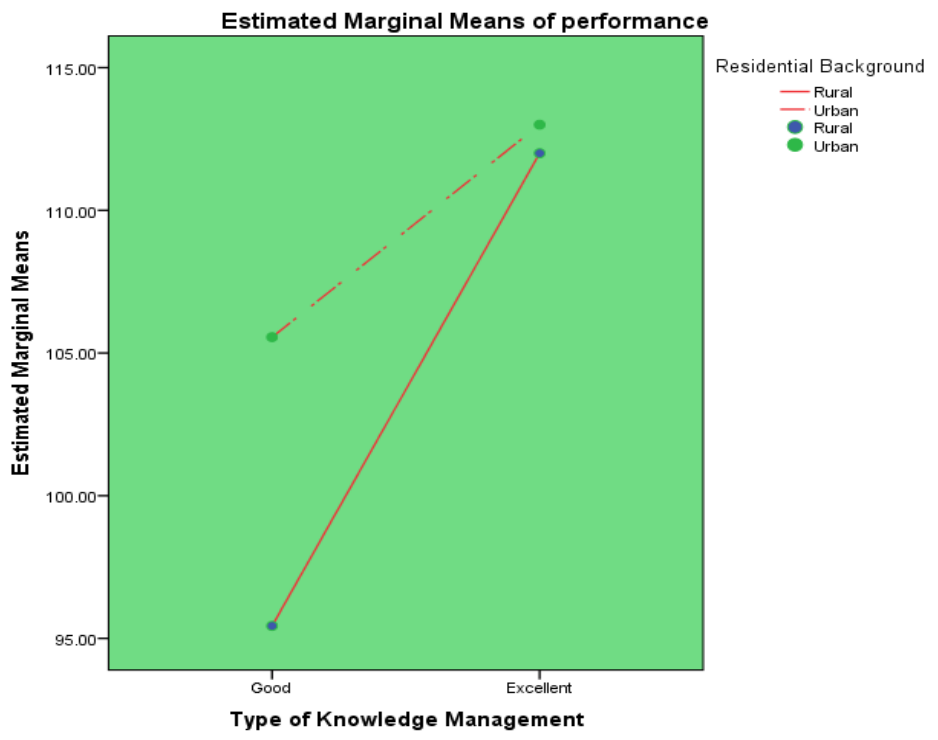

From graph 1.1 it can be seen that teacher trainees possessing Excellent Knowledge Management Skill performs better than those having Good Knowledge Management Skill.

Further from the above chart it can also be evident that teacher trainees whom belong to Urban Residential Background perform better then with those belong to Rural Residential Background in context of M-learning knowledge management programme.

\section{1.c Effect of interaction between M-Learning Knowledge Management and Residential Background on the Performance}

The F-Value for interaction between M-Learning knowledge management and Residential Background is 2.94 which is not significant at 0.05 level with $\mathrm{df}=1 / 48$. It indicates that there was a not significant effect of the resultant of interaction between M-Learning knowledge management and Residential Background on performance of teacher trainees. In light of this, the null hypothesis that 'there is not significant effect of interaction between M-learning knowledge management and residential background on performance' is not rejected. It may therefore be concluded that performance was found to be independent of interaction between M-learning knowledge management and Residential background.

1.2 Effect of M-Learning Knowledge Management, residential background and their interaction on teacher's performance (through students assessment)

The objective was to study the effect of M-Learning Knowledge Management, Residential Background and their interaction on performance. The performance was studied on the basis of assessment by school students. Thus data were analyzed with the help of factorial design 
To Study the Effect of M-Learning Knowledge Management Programme on the Performance of Teacher Trainees Belonging To Different Residential Backgrounds

ANOVA for the stated criteria and the results followed by their interpretations are given in the following captions.

As mentioned earlier the two levels of residential background were rural and urban. The data were analyzed with the help of $2 \times 2$ factorial designs ANOVA. The results are given in table.

Table 1.2 Summary of Factorial Design ANOVA for Performance. $(N=571)$

\begin{tabular}{|l|l|l|l|l|}
\hline Source of Variance & df & SS & MSS & F \\
\hline M-Knowledge Management & 1 & 1062.94 & 1062.94 & 15.87 \\
\hline Residential Background & 1 & 145.98 & 145.98 & 2.18 \\
\hline A x B & 1 & 158.70 & 158.70 & 2.37 \\
\hline Error & 567 & 66.96 & 66.96 & \\
\hline Total & 571 & & & \\
\hline
\end{tabular}

*Significant at 0.05 level

\section{2.a Effect of M-learning knowledge Management on performance}

From the table 1.2, it can be observed that the F-value for M-learning Knowledge Management is 15.87 which is significant. It reflects that mean score of performance differ significantly. Thus there was significant effect of M-Learning knowledge management on performance of teacher trainees. In this context, the null hypothesis that 'there is no significant effect of M-learning knowledge management on performance of teacher trainee's', is rejected. It may, therefore he said that the performance was affected significantly by M-learning knowledge management.

Graph no. 1.2. Effect of M-learning Knowledge Management and residential background on the performance.

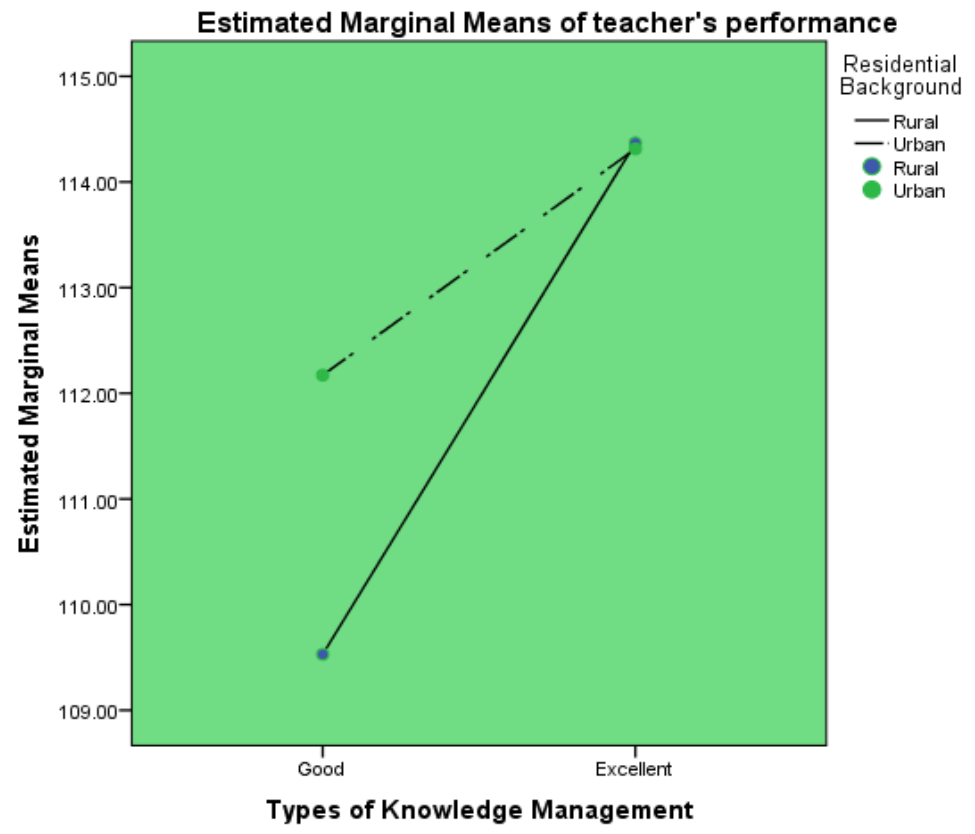




\section{To Study the Effect of M-Learning Knowledge Management Programme on the Performance of Teacher Trainees Belonging To Different Residential Backgrounds}

From graph 1.2 it can be seen that teacher trainees possessing Excellent Knowledge Management Skill performs better then with those having Good Knowledge Management Skill. In other words a Skill of Knowledge Management improves performance amongst teacher trainees.

\section{2b Effect of Residential Background on Performance}

The F-value for Residential Background is 2.18 (Vide Table 1.2) which is not significant. It indicates that the mean score of performance not differ significantly. So Residential Background did not influence the performance of teacher trainees from the viewpoint of school students. In this light, the null hypothesis that 'there is no significant effect of Residential Background on performance' is not rejected. It may therefore, be concluded that performance was found to be independent of Residential Background.

\section{2c Effect of interaction between M-learning knowledge management and Residential Background on Performance}

The F-Value for interaction between M-learning knowledge management and Residential Background is 2.37 which is not significant at 0.05 level with $\mathrm{df}=1 / 569$. It indicates that there was a no significant effect of the resultant of interaction between M-learning knowledge management and Residential Background on performance of teacher trainees. In light of this, the null hypothesis that there is not significant effect of interaction is not rejected.

\section{MAJOR FINDINGS}

- M-learning knowledge management skill in context to residential background found to affect performance amongst teacher trainees. For instance as M-learning knowledge management skill improves amongst teacher trainees with different residential background, their performance gets enhanced subsequently.

- Performance found to get affected by different residential background. i.e. teacher trainees with urban residential background perform better then teacher trainees belonging to rural background.

- Interaction between M-learning knowledge management and residential background doesn't affect performance of teacher trainees, in other words performance is found to be independent of reciprocation between M-learning knowledge management and residential background.

- From the perspective of school students M-learning knowledge management in context to residential background enhances performance amongst teacher trainees.

- School students experienced no difference in performance of teacher trainees belonging to different residential background. i.e. Urban and Rural.

- Interaction between M-learning knowledge management and residential background had no effect on performance among teacher trainees from school student's view. 


\section{To Study the Effect of M-Learning Knowledge Management Programme on the Performance of Teacher Trainees Belonging To Different Residential Backgrounds}

\section{LIMITATIONS}

1) The study was confined to teacher trainees of teacher training program on-going in one of the institute of teacher education.

2) Teacher trainees of regular teaching program were its participants.

3) Only teacher trainees elected teaching of English and Social Sciences were taken up for the study.

4) Study was conducted in only one of the teacher training institute, where only 52 participants were taken up for the study.

5) Only pre-service teachers were taken up for the present study.

\section{CONCLUSION}

This study was undertaken to find out effectiveness of M-learning knowledge management on the performance of teacher trainees. On the basis of the findings through self-assessment it was observed that M-learning knowledge management enhances performance of teacher trainees. Residential background of teacher trainees does affect their performance. Urban teacher trainees perform better than that of rural teacher trainees in reference to M-learning knowledge management. Other findings was drawn through student's perspective revels that M-learning knowledge management do effects performance of teacher trainees. And on the other hand students didn't find any difference between the performances of teacher trainees belonging to rural or urban residential background.

\section{BIBLIOGRAPHY}

Ammar, A., Ali, Zwain And Teong, L. Kong. (2012). Knowledge Management and Academic Performance in Iraqi HEIs: An Empirical Investigation. International Journal of Academic Research in Business and Social Sciences, Human Resource Management Academic Research Society, New York (IRA), 2(6), www.alacrastore.com.

Bajpai, Bhavna Raghvendra. (2011.) M-learning \& Mobile Knowledge Management: Emerging New Stages of e-Learning \& Knowledge Management. International Journal of Innovation, Management, and Technology, International Economics Development, Singapore, 2(1), 15. www.ieee.org.

Bouchard, Therese- Bouffard., Sophie, Parent And Serge, Larivee. (1991). Influence of SelfEfficacy on Self-Regulation and Performance among Junior and Senior High-School Age Students. International Journal of behavioural development, SAGE publication, California, 14(2), 153-164. www.jbd.sagepub.com.

Charles, Clemens Rulingand Raub, Steffen.(2010). The knowledge management tussle-speech communities and rhetorical strategies in the development of knowledge management. Journal of Information Technology, Association for Information Technology Trust, United Kingdom, 16 (2),113-130.www.emraldinsight.com. 


\section{To Study the Effect of M-Learning Knowledge Management Programme on the Performance of Teacher Trainees Belonging To Different Residential Backgrounds}

Chen, Hong-RenAndHui-Ling, Huang. (2010). User Acceptance of Mobile Knowledge Management Learning System: Design and Analysis. Educational Technology \& Society, International Forum of educational Technology \& Society, Canada, 13(3), 70-77. www.eric.ed.gov.

Dullas, Angelo Reyes. (2010). Academic performance and Self-Efficacy of Filipino Science High School Students on Mathematics and English Subjects. Social science research network, Social Science Electronic Publishing, Inc, California.www.papers.ssrn.com.

Parmar, Kamalnayan B. (2008). PDA: Valuable technology tool for student. Edutrack, Neelkamal publications PVT. LTD, India, 7 (5), 10-13.

Thomas, Kane J.; Wooten, Amy L.; Taylor, Eric S. And Tyler, John H. (2011). Evaluating Teacher Effectiveness. Education Next, Hoover Institution, Leland Stanford Junior University, United Kingdom, 11(3), 55-60. www.educationnext.org.

Traxler, John. (2011). learning in mobile age: A more and more mobile age. In David, Parsons, Combining E-learning and M-learning: new applications of blended educational resources, Information science reference, IGI global, Taiwan, P.15-27.

Wang, Minjuan; Ruimin, Shen., Daniel, Novak And Xiaoyan, Pan. (2008). The impact of mobile learning on students' learning behaviours and performance: Report from a large blended classroom. British Journal of Educational Technology, British Educational Research Association, United Kingdom, 40(4), 673-69. www.onlinelibrary.wiley.com. 